\title{
On the Oceanic Origin for the Enhanced Seasonal Cycle of SST in the Midlatitudes under Global Warming
}

\author{
FUKAI LIU \\ Key Laboratory of Physical Oceanography, Institute for Advanced Ocean Studies, and Qingdao National Laboratory for \\ Marine Science and Technology, and Department of Oceanography, Ocean University of China, Qingdao, China \\ JIAN LU \\ Atmospheric Sciences and Global Change Division, Pacific Northwest National Laboratory, Richland, Washington \\ YIYONG LUO \\ Key Laboratory of Physical Oceanography, Institute for Advanced Ocean Studies, and Qingdao National Laboratory for \\ Marine Science and Technology, and Department of Oceanography, Ocean University of China, Qingdao, China \\ YI HUANG \\ Department of Atmospheric and Oceanic Sciences, McGill University, Montreal, Canada
}

FENGFEI SONG

Atmospheric Sciences and Global Change Division, Pacific Northwest National Laboratory, Richland, Washington

(Manuscript received 19 February 2020, in final form 19 June 2020)

\begin{abstract}
Climate models project an enhancement in SST seasonal cycle over the midlatitude oceans under global warming. The underlying mechanisms are investigated using a set of partially coupled experiments, in which the contribution from direct $\mathrm{CO}_{2}$ effects (i.e., the response in the absence of wind change) and wind feedbacks can be isolated from each other. Results indicate that both the direct $\mathrm{CO}_{2}$ and wind effects contribute to the enhancement in the SST seasonal cycle, with the former (latter) being more important in the Northern Hemisphere (Southern Hemisphere). Further decomposition of the wind effect into the wind stress feedback and wind speed feedback reveals the importance of the wind stress-driven ocean response in the change of SST seasonal cycle, a result in contrast to a previous study that ascribed the midlatitude SST seasonal cycle change to the thermodynamic wind speed feedback. The direct $\mathrm{CO}_{2}$ effect regulates the SST seasonal cycle through the warming-induced shoaling in the annual mean mixed layer depth (MLD) as well as the MLD difference between winter and summer. Moreover, the surface wind seasonal cycle changes due solely to the direct $\mathrm{CO}_{2}$ effect are found to bear a great resemblance to the full wind response, suggesting that the root cause for the enhancement of the midlatitude SST seasonal cycle resides in the direct $\mathrm{CO}_{2}$ effect. This notion is further supported by an ocean-alone experiment that reproduces the SST seasonal cycle enhancement under a spatially and temporally homogeneous surface thermal forcing.
\end{abstract}

\section{Introduction}

Under anthropogenic forcing, comprehensive climate models have projected a significant change in the sea surface temperature (SST) seasonal cycle (Timmermann et al. 2004; Biasutti and Sobel 2009; Dwyer et al. 2012;

Corresponding authors: Jian Lu, jian.lu@pnnl.gov; Fukai Liu, fliu@ouc.edu.cn
Stine and Huybers 2012; Sobel and Camargo 2011; Carton et al. 2015; Liu et al. 2017; Thomas et al. 2018; Alexander et al. 2018), including an amplitude increase in SST seasonal cycle in the tropical Pacific, a phase delay and amplitude decrease in the high latitudes, and an amplitude increase in the midlatitudes. Given that the seasonal cycle accounts for over $80 \%$ of the total SST variance, the changes in SST seasonal cycle can have profound climatological and socioecological consequences 
(Longhurst 1995; Follows et al. 1996; Kushnir et al. 2002; Keeling et al. 2010).

By analyzing phase 3 of the Coupled Model Intercomparison Project (CMIP3) models, Sobel and Camargo (2011) found that the midlatitude SST changes in summer and winter with respect to the annual mean change perfectly mirror-image each other, an antisymmetry interpretable as an enhanced seasonal cycle, with greater (smaller) warming in summer (winter) hemisphere. Dwyer et al. (2012) also identified an amplitude enhancement of surface air temperature seasonal cycle in the midlatitudes, along with an amplitude reduction over the high latitudes. While the latter can be well explained by the increased effective heat capacity as a consequence of sea ice melting, the mechanisms for the enhanced surface temperature seasonal cycle in the midlaitudes are not well understood. Sobel and Camargo (2011) speculated that this increased amplitude of SST seasonal cycle is likely related to the increasing surface wind speed in the winter hemisphere and decreasing wind speed in the summer hemisphere, which in turn are associated with the expansion and weakening of the Hadley circulation. They inferred diagnostically that the above wind speed changes can thermodynamically induce local changes in SST via changing the turbulent heat fluxes. Similar attribution has also been employed in Dwyer et al. (2012), where they described a link between the enhanced SST seasonal cycle and a decrease in damping effects by turbulent and longwave heat fluxes. However, determining the causality from the diagnosing fully coupled model results is often difficult, as the wind change and the related surface heat flux change themselves can be the consequences of SST changes.

While the above studies highlighted the important role of atmospheric circulation and wind-related processes, a recent study by Chen and Wang (2015) proposed an oceanic origin for the intensified seasonal cycle in the North Pacific. Specifically, they analyzed mixed layer heat budget based on outputs from 35 climate models of the CMIP5 and demonstrated that global warming would induce a thinner mixed layer over the North Pacific. As a result, the incoming heat flux would work on a thinner mixed layer with smaller effective heat capacity, and thus even the same seasonal forcing would produce a stronger SST seasonal cycle. Alexander et al. (2018) reached a similar conclusion from investigating the SST change of northern oceans to global warming using CMIP5 and National Center for Atmospheric Research's (NCAR's) Community Earth System Model Large Ensemble Community Project (CESM-LENS) experiments, and further presented strong evidence for negative correlation between the increase of the monthly SST and the mean monthly mixed layer depth (MLD), which can also lead to an enhanced SST seasonal cycle. However, the analysis above focused only on the seasonal cycle changes over the midlatitude oceans in the North Hemisphere (NH), and it is unclear whether they are representative of the global midlatitude oceans in general. Further, Chen and Wang (2015) argued that the MLD reduction can result from either wind forcing (atmospheric origin) or pure oceanic adjustment to surface thermal forcing (oceanic origin) and therefore it is difficult to identify the root cause of the SST seasonal change from the mixed-layer heat budget, not to mention the quantification of the relative importance of atmospheric versus oceanic processes.

To overcome the above difficulties in understanding the mechanisms of the enhanced SST seasonal cycle, a more elaborate and constructive approach should be through partially coupled model experiments in which various factors are isolated and evaluated one at a time. To realize this isolation, this paper examines the response of the midlatitude SST seasonal cycle to $\mathrm{CO}_{2}$ quadrupling using NCAR's CESM, version 1 (CESM1), with a particular focus on the relative contribution from wind change and the oceanic adjustment to surface thermal forcing. The idea of the partially coupled experiments is realized through an overriding technique proposed in Lu and Zhao (2012), which can disable the wind change effect while allowing other atmospheric processes to still be interactive with the ocean. This overriding technique and the associated partially coupled experiments have been successfully used to understand the formation mechanisms for the oceanic temperature and circulation responses to global warming in previous studies (e.g., Luo et al. 2015, 2018; Liu et al. 2017; Liu et al. 2018). As will be shown later, although the wind change contributes to the enhanced SST seasonal cycle in the midlatitude oceans, it appears to be the consequence of the oceanic adjustment to surface thermal warming. This notion of oceanic origin is further supported by a set of ocean-alone experiment using only the ocean component of the CESM1 (see section 2 for details). Together, our experiments help shed light on the ultimate origin of the enhanced SST seasonal cycle under global warming.

The remainder of the paper is structured as follows. Section 2 describes the design of the partially coupled experiments as well as the ocean-alone experiments. Section 3 introduces the empirical orthogonal function (EOF)-based approach to quantify the spatial and temporal change in SST seasonal cycle. Analysis of the mechanisms responsible for the seasonal cycle change is then examined based on the partially coupled and ocean-alone experiments in section 4. Conclusions and discussion are presented in section 5 . 
TABLE 1. Experiment sets with CESM1 and POP2.

\begin{tabular}{|c|c|c|c|c|c|}
\hline Name & $\begin{array}{l}\text { Years of } \\
\text { model run }\end{array}$ & $\begin{array}{l}\text { Years of } \\
\text { analysis }\end{array}$ & \multicolumn{3}{|c|}{ Description } \\
\hline \multicolumn{6}{|c|}{ Fully coupled experiments (CESM1) } \\
\hline CTRL & 95 & $41-90$ & \multirow{2}{*}{\multicolumn{3}{|c|}{$\begin{array}{c}\text { Control with preindustrial } \mathrm{CO}_{2} \\
\text { Quadrupled } \mathrm{CO}_{2}\end{array}$}} \\
\hline $4 \times \mathrm{CO}_{2}$ & 95 & $41-90$ & & & \\
\hline \multicolumn{6}{|c|}{ Partially coupled experiments (overriding variables listed below; a 1-yr shift is applied) } \\
\hline & & & Wind stress & Wind speed & $\mathrm{CO}_{2}$ \\
\hline$\tau 1 \mathrm{w} 1 \mathrm{c} 1$ & 94 & $41-90$ & CTRL & CTRL & $1 \times$ \\
\hline$\tau 4 \mathrm{w} 4 \mathrm{c} 4$ & 94 & $41-90$ & $4 \times \mathrm{CO}_{2}$ & $4 \times \mathrm{CO}_{2}$ & $4 \times$ \\
\hline$\tau 1 \mathrm{w} 1 \mathrm{c} 4$ & 94 & $41-90$ & CTRL & CTRL & $4 \times$ \\
\hline$\tau 1 \mathrm{w} 4 \mathrm{c} 4$ & 94 & $41-90$ & CTRL & $4 \times \mathrm{CO}_{2}$ & $4 \times$ \\
\hline$\tau 4 \mathrm{w} 1 \mathrm{c} 4$ & 94 & $41-90$ & $4 \times \mathrm{CO}_{2}$ & CTRL & $4 \times$ \\
\hline \multicolumn{6}{|c|}{ Ocean-alone experiments (POP2) } \\
\hline OCTRL & 100 & $51-100$ & \multirow{2}{*}{\multicolumn{3}{|c|}{$\begin{array}{l}\text { Control with all atmospheric forcings prescribed with a } \\
\text { monthly climatology and no interaction with the } \\
\text { atmosphere is allowed. } \\
\text { Same as OCTRL, but with an extra } 1.5 \mathrm{~W} \mathrm{~m}^{-2} \text { heating into } \\
\text { the ocean surface }\end{array}$}} \\
\hline OHEAT & 100 & $51-100$ & & & \\
\hline
\end{tabular}

\section{Model and experiments}

The two baseline experiments consist of a preindustrial control (CTRL) and a 95-yr abrupt quadrupled $\mathrm{CO}_{2}$ simulation $\left(4 \times \mathrm{CO}_{2}\right)$ of CESM1 (Table 1$)$. The latter branches off from an arbitrary year from CTRL, with the atmospheric $\mathrm{CO}_{2}$ concentration being instantly quadrupled from $367 \mathrm{ppm}$ (preindustrial level) to $1468 \mathrm{ppm}$. The daily wind outputs from these two baseline simulations serve for overriding purpose in the following partially coupled experiments. The atmospheric component of CESM1, the Community Atmosphere Model version 5 (CAM5), has a resolution of $1.9^{\circ}$ latitude $\times 2.5^{\circ}$ longitude. The ocean component, the Parallel Ocean Program version 2 (POP2), has a nominal $1^{\circ}$ horizontal resolution with meridional grid spacing decreasing to $\sim 0.3^{\circ}$ at the equator. Vertically, it has 60 uneven vertical levels with the highest resolution of $10 \mathrm{~m}$ near the surface.

\section{a. Partially coupled experiments}

The SST response in $4 \times \mathrm{CO}_{2}$ can result from both the direct warming effect of $\mathrm{CO}_{2}$ and wind-related feedbacks; this motivates us to employ a partial coupling approach (Lu and Zhao 2012; Liu et al. 2018) to separate the above effects. The partial coupling is realized through overriding the full time series of a certain variable at the air-sea interface with those from the fully coupled simulations (CTRL or $4 \times \mathrm{CO}_{2}$ ) to disable the targeted process or feedback. Three variables are considered for the overriding: wind stress $\tau$, wind speed $w$, and $\mathrm{CO}_{2} c$. The separation of wind stress from wind speed is because the former modifies SST via dynamically changing ocean circulation and hence thermal structure, whereas the latter influences ocean-atmosphere thermal coupling and the SST pattern through the wind speed in the bulk formula of turbulent heat fluxes. These two effects work differently in the model, and thus the separation of wind stress and wind speed effects can be realized through overriding experiments as detailed below. Even in the absence of the wind-related feedbacks above, the increase of $\mathrm{CO}_{2}$ forcing can still cause SST changes via (i) exerting radiative forcing-that is, the spatially and temporally homogeneous $\mathrm{CO}_{2}$ concentration can bring about inhomogeneous radiative forcing (Huang et al. 2016) and thus possible consequence in SST seasonality—or (ii) the ocean dynamical adjustments to the surface radiative forcing, such as the thermally forced ocean circulation changes. This $\mathrm{CO}_{2}$ forcing effect in the absence of wind change is referred to the direct $\mathrm{CO}_{2}$ effect in the context of this study. A schematic diagram of the partitioning of the full response into four possible processes is presented in Fig. 1. To isolate the direct $\mathrm{CO}_{2}$ effect, the wind stress-driven ocean feedback, and wind speed feedback from the full response, five partially coupled experiments are designed and performed as follows:

1) $\tau 1$ w1c1: This run is the same as CTRL but with a disrupted temporal coherence between surface wind and the oceanic condition, which is realized through overriding the surface wind with a 1-yr forward shift. Note the time shift only serves to interrupt the temporal coherence and can be any integer number of years. Without the 1-yr shift, this resultant run would be the identical supplication of the CTRL run. The 1-yr shift works to obstruct the temporal coherence between surface wind (both wind stress and wind 


\section{Coupled climate system under $\mathrm{CO}_{2}$ forcing}

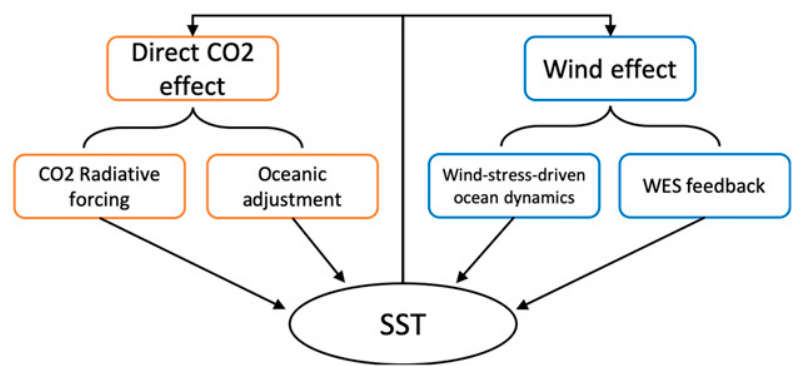

FIG. 1. Schematic showing a parallelized decomposition for the SST response. The forcing of increased $\mathrm{CO}_{2}$ concentration affects SST through direct $\mathrm{CO}_{2}$ effect (see text for definition) and wind effect. The direct $\mathrm{CO}_{2}$ gives rise to SST changes through (i) exerting direct radiative forcing, and (ii) pure oceanic dynamical adjustment to the aforementioned radiative effect. On the other hand, the total wind effect can also be decomposed into two components: the wind stress-driven ocean dynamical adjustment and wind speed feedback through influencing turbulent heat fluxes. The four effects, decomposed through partial coupling experiments, are additive to the fully coupled SST response to $\mathrm{CO}_{2}$ forcing.

speed) and oceanic variabilities and hence to disable the feedbacks through wind stress and wind speed. As a consequence, this will cause a climate drift, a drift being significant enough to be accounted for when it comes to extracting climate feedback signals, but not large enough to change the mean climate substantially. Therefore, the results from the partially coupled simulations cannot be directly compared with the fully coupled simulations, only the overriding runs can be contrasted against each other, so that the common drift residing in them can be cancelled out. As will be shown later, although climate drift exists in each individual partially coupled experiment, the corresponding SST seasonal cycle response $(\tau 4 \mathrm{w} 4 \mathrm{c} 4-$ $1 \mathrm{w} 1 \mathrm{c} 1)$ can faithfully capture all the major features of the response in the fully coupled context (i.e., $4 \times$ $\mathrm{CO}_{2}-\mathrm{CTRL}$ ). More details documenting the overriding technique can be found in Liu et al. (2018).

2) $\tau 4 \mathrm{w} 4 \mathrm{c} 4$ : like $4 \times \mathrm{CO}_{2}$ but the wind variables are overridden with a 1-yr forward shift so that the temporal coherence is also interrupted.

3) $\tau 1$ w1c4: like $4 \times \mathrm{CO}_{2}$ but the wind variables are overridden by those from CTRL with a 1-yr forward shift.

4) $\tau 1 \mathrm{w} 4 \mathrm{c} 4$ : like $4 \times \mathrm{CO}_{2}$, but the wind stress (wind speed) is overridden by that from CTRL $\left(4 \times \mathrm{CO}_{2}\right)$ with a 1-yr forward shift.

5) $\tau 4 \mathrm{w} 1 \mathrm{c} 4$ : like $4 \times \mathrm{CO}_{2}$, but the wind speed (wind stress) is overridden by that from CTRL $\left(4 \times \mathrm{CO}_{2}\right)$ with a 1-yr forward shift.

All the partially coupled experiments are initialized from the same initial atmospheric and oceanic states of
CTRL and then integrated for 94 years, and the monthly average over years 41-90 is examined. The details of these experiments are also summarized in Table 1. With this set of experiments, we can decompose the total SST response to $\mathrm{CO}_{2}$ quadrupling into contributions from (i) wind stress effect $(\tau 4 \mathrm{w} 1 \mathrm{c} 4-\tau 1 \mathrm{w} 1 \mathrm{c} 4)$, (ii) wind speed effect $(\tau 1 \mathrm{w} 4 \mathrm{c} 4-\tau 1 \mathrm{w} 1 \mathrm{c} 4)$, and (iii) the direct $\mathrm{CO}_{2}$ effect ( $\tau 1 \mathrm{w} 1 \mathrm{c} 4-\tau 1 \mathrm{w} 1 \mathrm{c} 1)$; the sum of (i) and (ii) is referred to as the total wind effect. It is important to note that the wind stress and wind speed effects can also be derived as $\tau 4 \mathrm{w} 4 \mathrm{c} 4-\tau 1 \mathrm{w} 4 \mathrm{c} 4$ and $\tau 4 \mathrm{w} 4 \mathrm{c} 4-\tau 4 \mathrm{w} 1 \mathrm{c} 4$, respectively, with virtually identical results (not shown), vindicating the linearity and additivity of decomposition framework here. We do not perform overriding case $\tau 4 \mathrm{w} 4 \mathrm{c} 1$ to vindicate the linearity of the direct $\mathrm{CO}_{2}$ effect by contrasting it against $\tau 4 \mathrm{w} 4 \mathrm{c} 4$. But our previous experience with a similar overriding approach (Lu and Zhao 2012) gives us some confidence that linearity should hold sufficiently well for the decomposition purpose here. The actual results do bear out the linearity well. The five overriding experiments are the necessary complications one must delve into to untangle the feedbacks of interest from a coupled climate system where everything influences everything else (Roe 2009).

\section{b. Ocean-alone experiments}

To further assess the role of the ocean dynamical adjustments in regulating the SST seasonal cycle response, a pair of ocean-alone experiments (including OCTRL and OHEAT; see Table 1) are conducted using only the ocean component of the CESM1. In the OCTRL run, all atmospheric forcings (including winds, air temperature, air pressure, specific humidity, precipitation rate, air density, and net shortwave and downward longwave radiations) are prescribed as the daily climatology of CTRL, and thus no interaction with the atmosphere is allowed. The OHEAT run is forced the same way as OCTRL but with an additional spatially and temporally homogeneous heat flux $\left(1.5 \mathrm{~W} \mathrm{~m}^{-2}\right)$ into the ocean surface. This pair of ocean-alone experiments are integrated for 100 years and the monthly average of the last 50 years is used for analysis. Since the heat flux perturbation is uniform in space and time, any temporal and spatial structures in the SST anomalies due to OHEAT minus OCTRL can only be attributed to the oceanic adjustment.

\section{SST seasonal cycle change captured by the first EOF}

Before exploring the changes of the SST seasonal cycle under quadrupling $\mathrm{CO}_{2}$, we briefly examine the changes in the annual mean SST (Fig. 2a). A comparison of annual mean SST change in CESM and CMIP5 


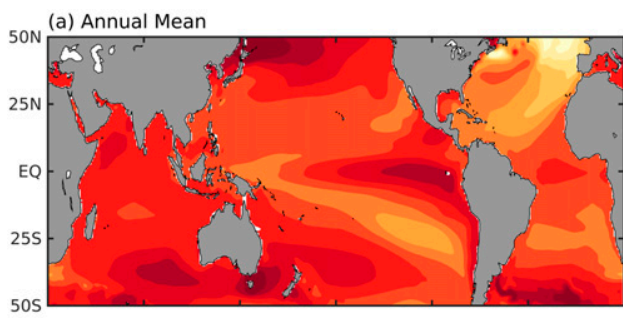

(b) JFM mean - Annual Mean

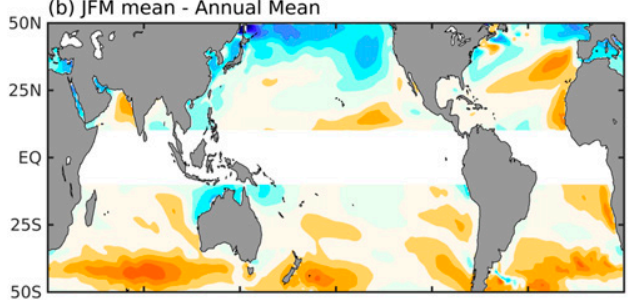

(c) JAS mean - Annual Mean

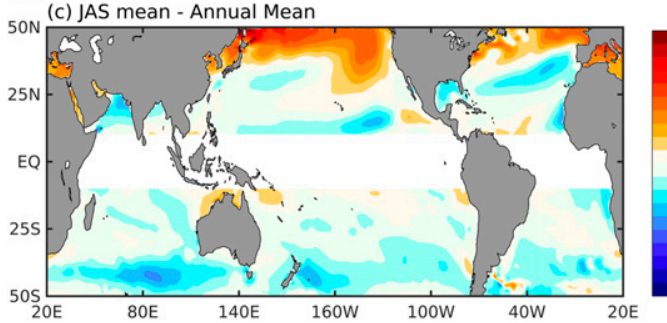

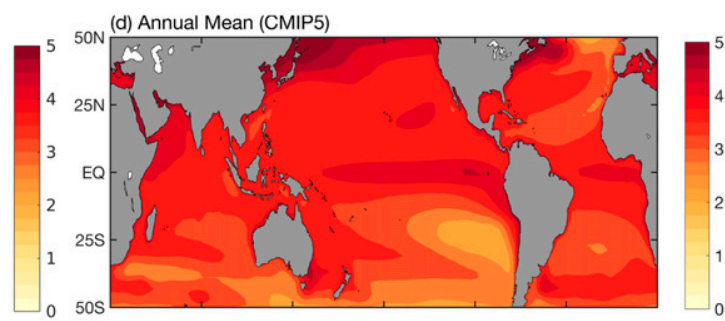

(e) JFM mean - Annual Mean (CMIP5)
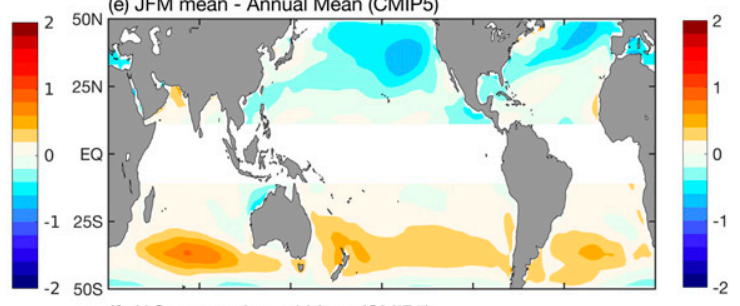

(f) JAS mean - Annual Mean (CMIP5)

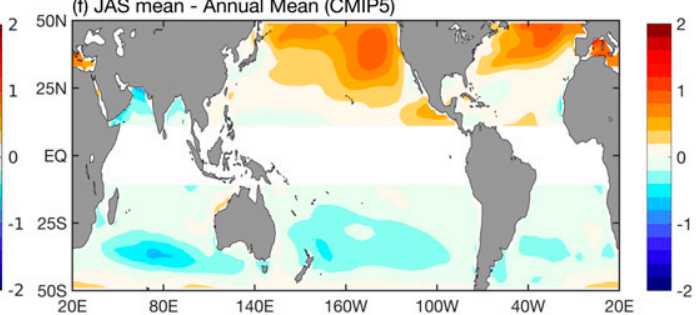

FIG. 2. SST response (K) to $\mathrm{CO}_{2}$ quadrupling in (left) CESM1 and (right) the ensemble mean of models from phase 5 of the Coupled Model Intercomparison Project (CMIP5): (a),(d) annual mean change, (b),(e) seasonal change in January-March (JFM), and (c),(f) seasonal change in July-September (JAS). The CMIP5 ensemble response is based on abrupt $4 \mathrm{xCO} 2$ and piControl runs with 36 CMIP5 models.

multimodel ensemble mean is shown in Figs. 2a and 2b. Note that CESM1 simulates a stronger warming hole in the North Atlantic, due to considerable intermodel variability in AMOC behavior among CMIP5 models (Menary and Wood 2018). Other than that, the SST change simulated by CESM1 is overall representative of the CMIP5 results, characterized by an El Niño-like warming pattern in the tropical Pacific, a maximum warming in the northern North Pacific, and a minimum warming over the southeast subtropical Pacific. These features and their corresponding forming mechanisms have been well described in many previous studies (e.g., Xie et al. 2010; Lu and Zhao 2012; Luo et al. 2015, 2017).

Following Sobel and Camargo (2011), we subtract the annual mean SST response from the seasonal mean to explore the relative change in different seasons (Figs. 2b,c). Since we focus on the SST season cycle that in the form of a sinusoid with a period of one year, only results in the extratropic between $10^{\circ}$ and $50^{\circ}$ are presented, where the solar insolation is dominated by the annual harmonic (Trenberth 1983). With the annual mean response excluded, the seasonal SST response exhibits an overall antisymmetric pattern that exhibits a mirror image about the equator: the SST change between $20^{\circ}$ and $50^{\circ}$ features a relative warming in the summer hemisphere and a relative cooling in the winter hemisphere, denoting a significant enhancement of seasonal cycle in both hemispheres; on the contrary, the SST change between $10^{\circ}$ and $20^{\circ}$ is relatively weak and even tends to reduce the seasonal cycle. Despite the above antisymmetry, differences do exist between the two hemispheres, with the $\mathrm{SH}$ seasonal change being more zonally symmetric than that of the NH. In North Pacific, the SST seasonal cycle enhancement is characterized by an incomplete horseshoe-shaped pattern that bends southward near the American coast, with its southern edge confined by the climatological Kuroshio Extension. In the North Atlantic, a seasonal cycle reduction extends from the Caribbean Sea to the northwest coasts of Africa, a region known as the Atlantic hurricane main development region (Mann and Emanuel 2006), sandwiched between a sizable seasonal cycle enhancement in the subpolar gyre and a weak enhancement in the tropics between $10^{\circ}$ and $15^{\circ} \mathrm{N}$. In general, the SST seasonal cycle in CESM changes between $20^{\circ}$ and $50^{\circ}$ in both amplitude and pattern agree well with those derived from CMIP5 simulations (Figs. 2e,f) and CMIP3 simulations analyzed by Sobel and Camargo (2011). The robustness of the midlatitude signal prompts us to focus this study on the mechanisms behind the midlatitude 
enhancement of the SST seasonal cycle under $\mathrm{CO}_{2}$ forcing.

To better quantify the changes in the SST seasonal cycle, we perform an EOF analysis on the monthly SST in CTRL and its monthly changes (Fig. 3). The seasonal cycle can be well captured by the first EOF of the monthly SST, as it explains $87 \%$ of the total variance of the mean seasonal evolution of the monthly SSTs (Fig. 3a). Interestingly, the first EOF mode of monthly SST differences in $4 \times \mathrm{CO} 2-$ CTRL (Fig. 3b) accounts for $58 \%$ of the total variance, capturing most of the major features presented in Figs. $2 b$ and $2 c$. Besides, the corresponding normalized principal component (PC; bars in Fig. 3c) peaks in September and March, perfectly coinciding with the climatological seasonal cycle (line in Fig. 3c), clearly indicating an intensification of the seasonal cycle. Since the PCs of monthly climatology (lines) and changes (bars) are all normalized to unit standard deviation, the patterns in Figs. $3 a$ and $3 b$ indicate the magnitude. Comparison between Figs. $3 b$ and $3 a$ clearly shows that the largest enhancement occurs around $45^{\circ} \mathrm{N}$ in the North Pacific (SST seasonal cycle over $44^{\circ}-46^{\circ} \mathrm{N}$, $140^{\circ} \mathrm{E}-120^{\circ} \mathrm{W}$ increased by $17 \%$ ) and North Atlantic (SST seasonal cycle over $44^{\circ}-46^{\circ} \mathrm{N}, 60^{\circ} \mathrm{W}-0^{\circ}$ increased by $16 \%$ ), and around $40^{\circ} \mathrm{S}$ in the Southern Ocean (SST seasonal cycle over $39^{\circ}-41^{\circ} \mathrm{S}$ increased by $14 \%$ ). Therefore, the spatial and temporal distributions of seasonal cycle change can be well captured by a single EOF mode and its associated normalized PC, yielding a convenient and reliable metric for quantifying the seasonal cycle change. Comparing Fig. 3a with Fig. 3b, another interesting feature is the overall poleward shift of the seasonal cycle pattern under $\mathrm{CO}_{2}$ forcing. In particular, shifting the climatological EOF pattern (Fig. 3a) poleward can largely capture the EOF pattern of the forced change (Fig. 3b), with an exception over the eastern portion of the North Pacific basin, where the westerly jet there has been found to extend downstream and shift slightly equatorward (Neelin et al. 2013). This shift in SST EOF pattern is also in keeping with the projection that the summer westerlies shift more poleward than the winter ones under global warming (Simpson et al. 2014).

\section{Oceanic origin for the SST seasonal cycle changes}

Figure 4 partitions the SST seasonal cycle change through the partially coupled experiments. Note that the total seasonal cycle change in the fully coupled simulations is well reproduced by the replication (comparing Figs. 4a,f with Figs. 3b,c), that is, the summation of the components of the wind stress effect, wind speed effect, (a) EOF1 (87\%)

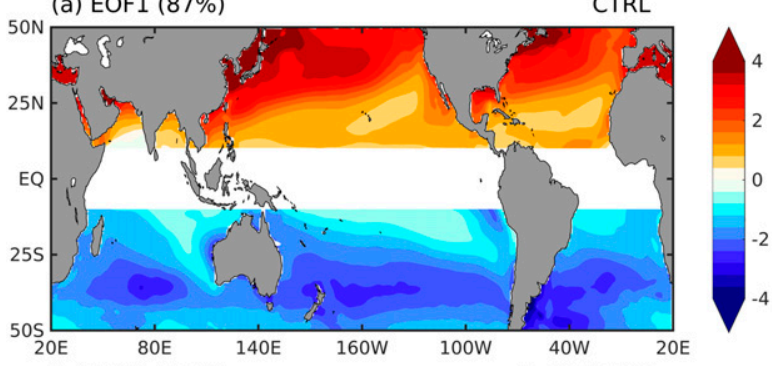

(b) EOF1 (58\%)
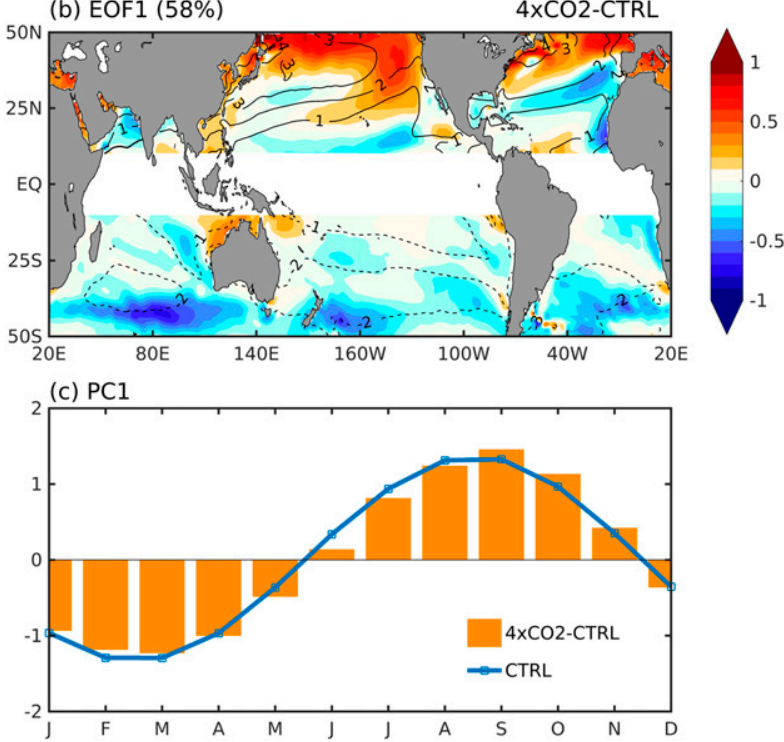

FIG. 3. The first EOF of (a) SST monthly climatology in CTRL and (b) the changes in SST monthly climatology in $4 \times \mathrm{CO}_{2}-$ CTRL, and (c) their corresponding PC time series (line for climatology and bars for changes). Superimposed in (b) is the first EOF of SST monthly climatology in CTRL [as in (a); contour interval $(\mathrm{CI})=1 \mathrm{~K}])$. Note that the time series in this and the following figures are normalized to have unit standard deviation, so that the information of the amplitude of the annual cycle and its change is carried by the loadings of the EOF patterns (unit: K).

and direct $\mathrm{CO}_{2}$ effect, each being extracted from the appropriate pair of overriding runs (as detailed in section 2a), indicating that the forcing-response relationship in this work is overall linear. By design, these three components are linearly additive and each individual of them can also be compared with the total seasonal cycle change in the replication. Given the phase-locking of the normalized PC time series with the climatological PC in all the cases (bars in right panels), the EOF1 patterns of the decomposed components also add up accurately to the replication EOF1. This allows us to quantify the respective contribution to the total SST seasonal cycle change from the wind stress, wind speed, and direct $\mathrm{CO}_{2}$ effects. Comparing Figs. $4 \mathrm{~b}$ and $4 \mathrm{c}$, one can see that both direct $\mathrm{CO}_{2}$ and total wind effects contribute to the seasonal cycle enhancement. Specifically, 

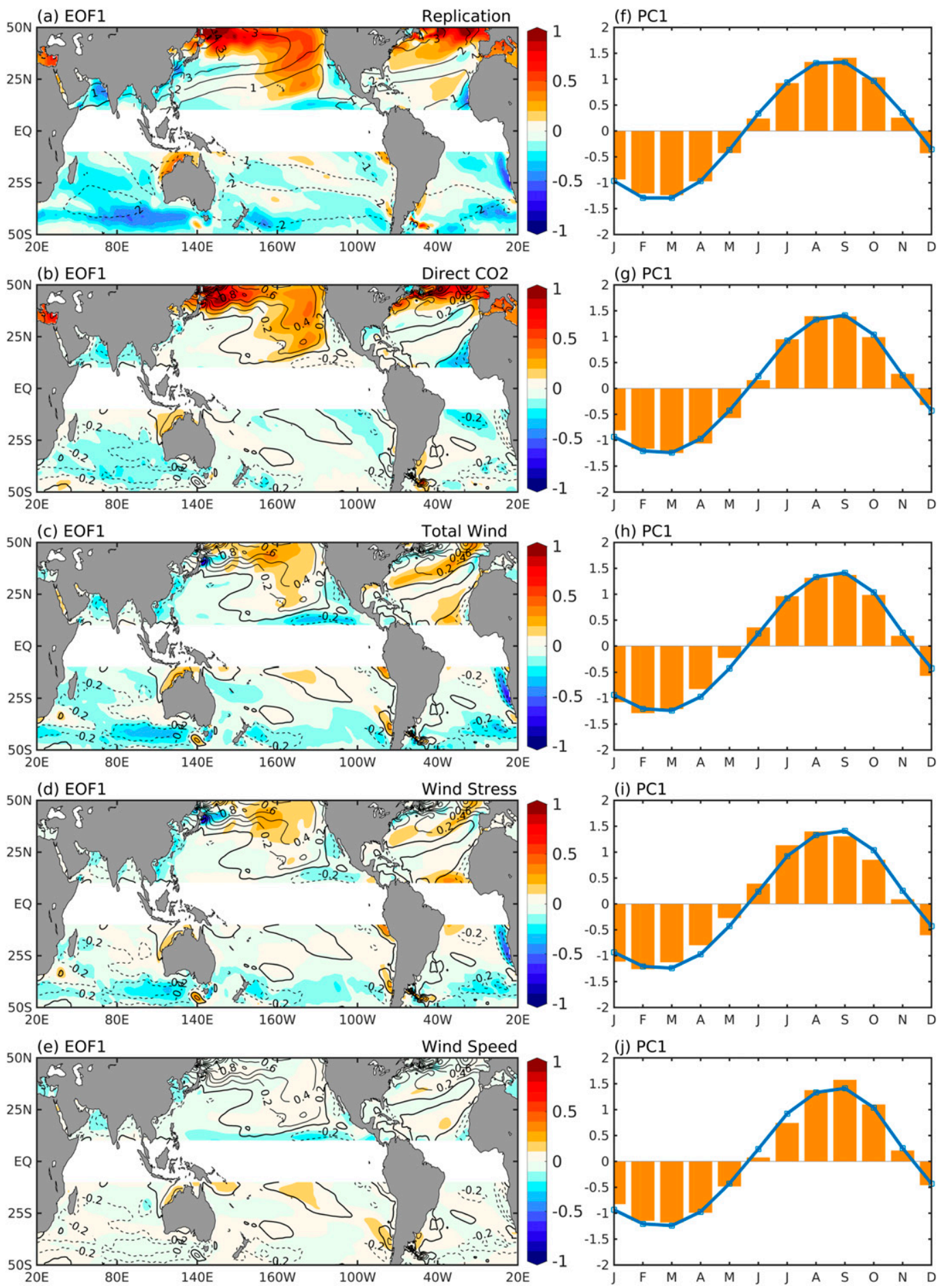

FIG. 4. The first EOF of the changes in SST monthly climatology (color; K) in (a) replication of total response $(\tau 4 \mathrm{w} 4 \mathrm{c} 4-\tau 1 \mathrm{w} 1 \mathrm{c} 1),(\mathrm{b})$ direct $\mathrm{CO}_{2}$ effect $(\tau 1 \mathrm{w} 1 \mathrm{c} 4-\tau 1 \mathrm{w} 1 \mathrm{c} 1)$, (c) total wind effect $(\tau 4 \mathrm{w} 4 \mathrm{c} 4-\tau 1 \mathrm{w} 1 \mathrm{c} 1+\tau 1 \mathrm{w} 1 \mathrm{c} 4-$ $\tau 1 \mathrm{w} 1 \mathrm{c} 1)$, (d) wind stress effect ( $\tau 4 \mathrm{w} 1 \mathrm{c} 4-\tau 1 \mathrm{w} 1 \mathrm{c} 4)$, and (e) wind speed effect ( $\tau 1 \mathrm{w} 4 \mathrm{c} 4-\tau 1 \mathrm{w} 1 \mathrm{c} 4)$. Superimposed in (a) is the first EOF of SST monthly climatology in CTRL (same as Fig. 3a; CI =1 K), and superimposed in (b)-(e) is the first EOF of the changes in SST monthly climatology in the replication [same as the color in (a); CI = 0.2 K] Their corresponding normalized PC time series are shown in the right panels (bars for changes and lines for climatology). 

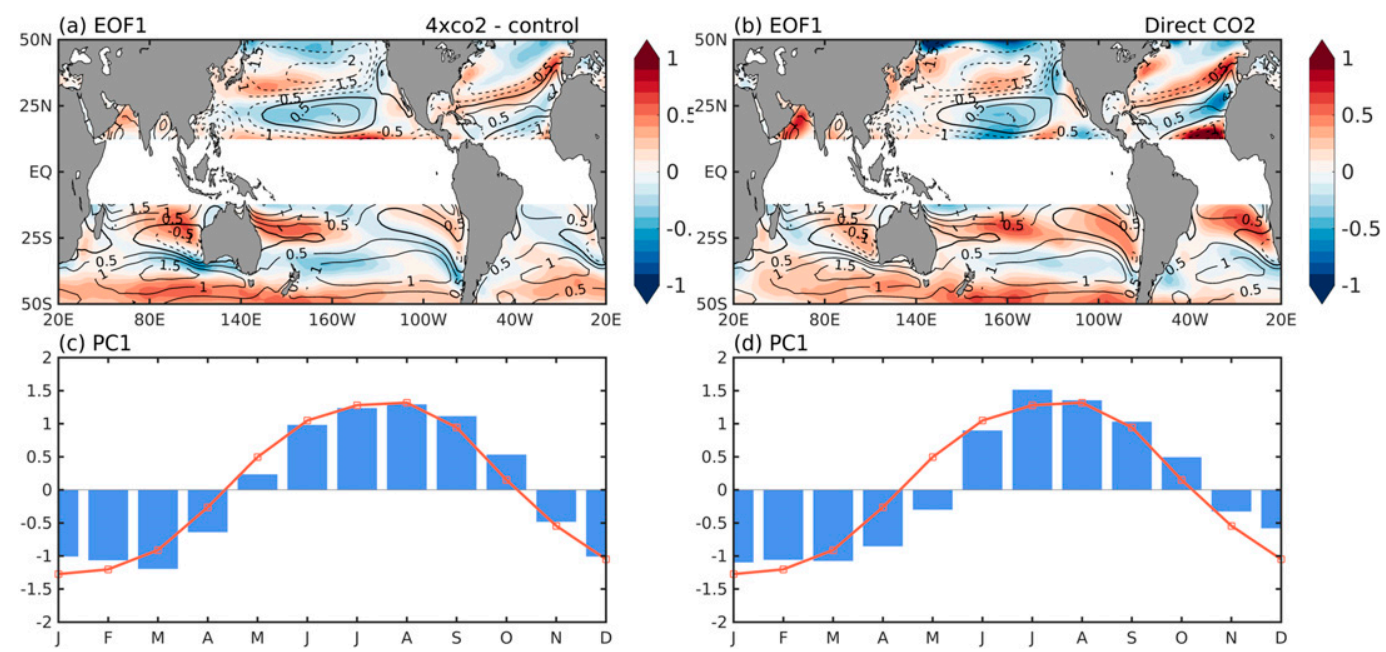

FIG. 5. The first EOF of the changes in 10-m wind speed monthly climatology (color; $\mathrm{m} \mathrm{s}^{-1}$ ): (a) total response $\left(4 \times \mathrm{CO}_{2}-\mathrm{CTRL}\right)$, and (b) direct $\mathrm{CO}_{2}$ effect $(\tau 1 \mathrm{w} 1 \mathrm{c} 4-\tau 1 \mathrm{w} 1 \mathrm{c} 1)$. Superimposed is the first EOF of the monthly climatology in CTRL $\left(\mathrm{CI}=0.5 \mathrm{~m} \mathrm{~s}^{-1}\right)$. Their corresponding normalized PC time series are shown in the lower panels (bars for changes and line for climatology).

the direct $\mathrm{CO}_{2}$ effect dominates the horseshoe-shaped enhancement in the North Pacific, the strong enhancement in the subpolar North Atlantic, and, to a lesser extent, the enhancement in the subtropical southern oceans. In contrast, the total wind effect is more important in the SST seasonal cycle enhancement in southern oceans, especially near the northern flank of the Antarctic Circumpolar Current, suggesting the importance of changing westerly winds there.

\section{a. Wind stress effect versus wind speed effect}

Figures $5 \mathrm{a}$ and $5 \mathrm{c}$ presents the climatological $10-\mathrm{m}$ wind speed seasonal cycle in CTRL and its changes under quadrupling $\mathrm{CO}_{2}$. The seasonal cycle of climatological wind speed (contours) is featured with a meridional dipole pattern centered around $25^{\circ}$ latitude in both North Pacific and North Atlantic, reflecting an overall weakening of the midlatitude westerlies and subtropical trade wind in summer compared to winter. In the Southern Hemisphere (SH), the summer weakening of the westerlies is much more pronounced in the midlatitude. Under the $\mathrm{CO}_{2}$ forcing, the EOF1 pattern of the wind speed change is characterized by a meridional tripole (shading), which, added onto the climatological dipole (contours), would shift the spatial structure of the wind speed seasonal cycle toward higher latitudes. The shift feature is especially clear in the $\mathrm{SH}$, while the $\mathrm{NH}$ change also features a reduction of the wind speed seasonal cycle in the subtropical latitudes between $15^{\circ}$ and $30^{\circ}$. According to the hypothesis proposed by Sobel and Camargo (2011), the enhanced SST seasonal cycle in the midlatitudes can be the thermodynamic consequences of enhanced wind speed seasonal cycle. Supposedly, the increasing (decreasing) surface winds in the winter (summer) hemisphere (Figs. 5a,c) would cool (warm) the SST through enhanced (reduced) evaporation, intensifying the climatological SST seasonal cycle. However, further decomposition shows that the total wind effect is dominated by changes in wind stress, but not wind speed (cf. Figs. 4d and 4e), with the latter only playing a discernable role in the seasonal cycle reduction within a tropical stripe between $10^{\circ}$ and $15^{\circ}$ (Fig. 4e).

How can wind stress give rise to the SST seasonal cycle enhancement as shown in Fig. 4d? In an attempt to address this question, we examine in Fig. 6 the seasonal cycle change in wind stress curl to infer the wind curlinduced Ekman pumping effect. It is well known that a cyclonic wind stress can pump the submixed layer water upward, resulting in a cooling at surface, and vice versa. However, the Ekman pumping effect implied by the wind stress curl change in Fig. 6 suggests that it works against the SST seasonal cycle enhancement over most of the midlatitude oceans. For instance, in the SH midlatitudes, the cyclonic (corresponding to negative shading in the SH in Fig. 6a) wind stress curl anomaly in summer relative to winter can lead to cold upwelling, thereby projecting on a reduction of the midlatitude SST seasonal cycle, just opposite to what the wind stress effect actually produces. Therefore, it must be processes other than Ekman pumping that are responsible for the enhanced midlatitude SST seasonal cycle enhancement. Further inspection suggests annual mean change in wind stress might be the main culprit. Figure 7 illustrates a 

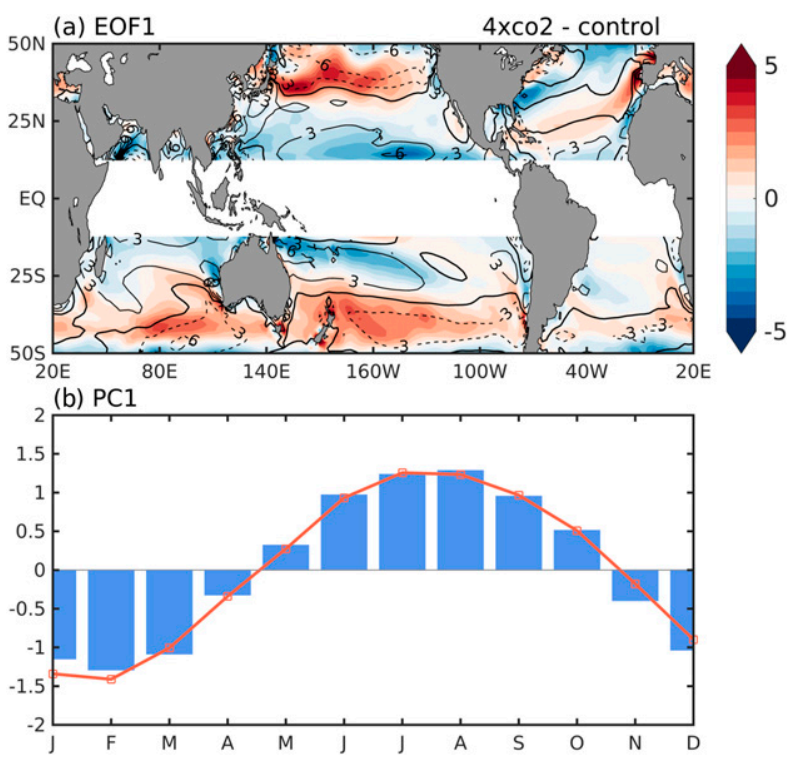

FIG. 6. The first EOF of the changes in wind stress curl monthly climatology in total response (color; $10^{-8} \mathrm{~N} \mathrm{~m}^{-3} ; 4 \times \mathrm{CO}_{2}-$ CTRL). Superimposed is the first EOF of the monthly climatology of wind stress curl in CTRL $\left(\mathrm{CI}=3 \times 10^{-7} \mathrm{~N} \mathrm{~m}^{-3}\right)$. Their corresponding normalized PC time series are shown in the lower panels (bars for changes and line for climatology). Note that positive (negative) wind stress curl produces cold upwelling (warm downwelling) in the $\mathrm{NH}$, while the opposite is true in the $\mathrm{SH}$.

good spatial correspondence (pattern correlation is 0.5 ) between the annual mean change in wind stress (Fig. 7a) and the annual mean change in MLD (Fig. 7b) in $\tau 4 \mathrm{w} 1 \mathrm{c} 4-\tau 1 \mathrm{w} 1 \mathrm{c} 4$, especially in the $\mathrm{SH}$ where the wind stress effect has a relatively greater contribution (pattern correlation is 0.6 ). The MLD here is defined using a density criterion as the depth at which the temperature is $0.03 \mathrm{~kg} \mathrm{~m}^{-3}$ smaller than density at a reference depth of $10 \mathrm{~m}$ (de Boyer Montégut et al. 2004). In response to the weakening of wind stirring in midlatitudes, the MLD there is expected to shoal (Thomson and Fine 2003), which decreases the effective heat capacity of upper ocean and thus leads to intensified SST seasonal cycle. Based on the analysis above, it is arguable that wind mechanical stirring is more important than the thermodynamic wind speed feedback in determining the SST seasonal cycle response to global warming in the midlatitudes. Nevertheless, we cannot rule out the possibility that wind stress can change the MLD through indirect wind stress-induced buoyancy flux, the isolation of which is beyond the capability of this set of overriding experiments.

\section{b. Wind effect versus direct $\mathrm{CO}_{2}$ effect}

Notwithstanding the parallelized decomposition used herein (Fig. 1), evidence emerges that the wind change

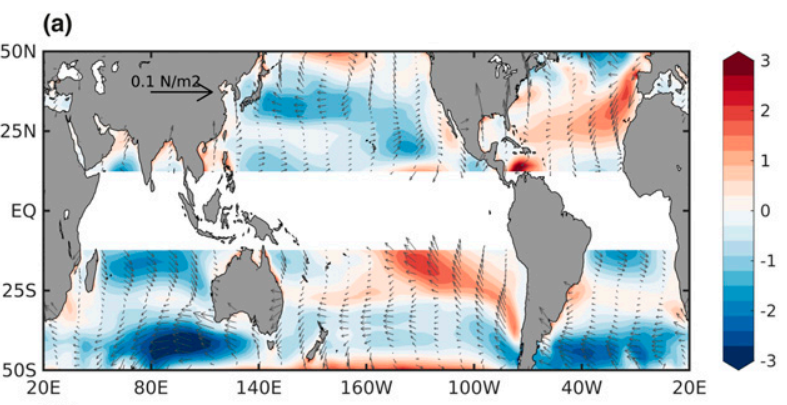

(b)

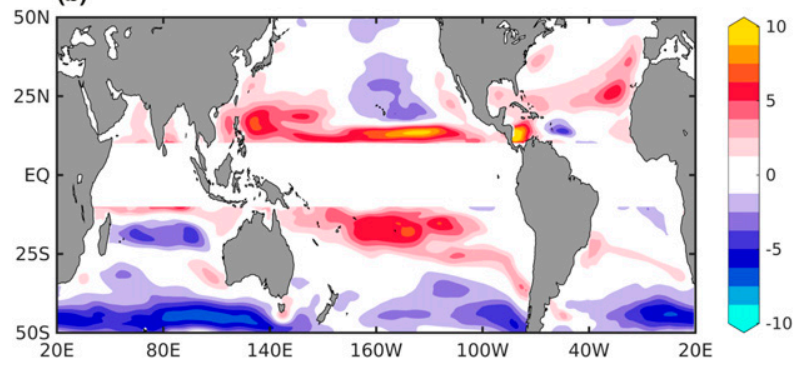

FIG. 7. (a) Annual mean change in wind stress (vectors) and its magnitude (color; $10^{-2} \mathrm{~N} \mathrm{~m}^{-2}$ ) in $4 \times \mathrm{CO}_{2}-$ CTRL. (b) annual mean change in mixed layer depth (MLD; $\mathrm{m}$ ) due to wind stress effect $(\tau 4 \mathrm{w} 1 \mathrm{c} 4-\tau 1 \mathrm{w} 1 \mathrm{c} 4)$. MLD is defined as the depth at which the potential density is $0.03 \mathrm{~kg} \mathrm{~m}^{-3}$ lower than density at $10 \mathrm{~m}$.

itself is not independent of, but rather is instigated by, the direct $\mathrm{CO}_{2}$ effect. Figure 5 compares the seasonal cycle change in $10-\mathrm{m}$ wind speed between the response in a fully coupled setting (Figs. 5a,c; $4 \times \mathrm{CO}_{2}-$ CTRL) and in a wind feedback disabled one (Figs. 5b,d; $\tau 1 \mathrm{w} 1 \mathrm{c} 4-\tau 1 \mathrm{w} 1 \mathrm{c} 1)$. It is remarkable to note the great resemblance in the pattern of the enhanced $10-\mathrm{m}$ wind speed seasonal cycle between the two cases, and this resemblance also exists in the corresponding wind stress comparison (not shown). Note that, in $\tau 1 \mathrm{w} 1 \mathrm{c} 4-$ $\tau 1 \mathrm{w} 1 \mathrm{c} 1$, the ocean sees no change in the wind due to the overriding, but still can produce a similar wind change pattern on its own under $\mathrm{CO}_{2}$ forcing. This evidence arguably excludes the wind stress-induced ocean dynamical feedback and wind speed feedback as the origin for the midlatitude wind response under global warming. By corollary, the wind stress-related SST seasonal cycle changes should be viewed as the consequence of the wind stress-related feedback, which itself may be traced back to the direct $\mathrm{CO}_{2}$ effect.

\section{c. Radiative forcing versus pure ocean dynamical adjustments}

The above results from the partially coupled experiments show that the direct $\mathrm{CO}_{2}$ effect is the main factor in determining the enhancement of the SST seasonal cycle. However, the direct $\mathrm{CO}_{2}$ effect can affect the SST change through multiple ways and two possible pathways 

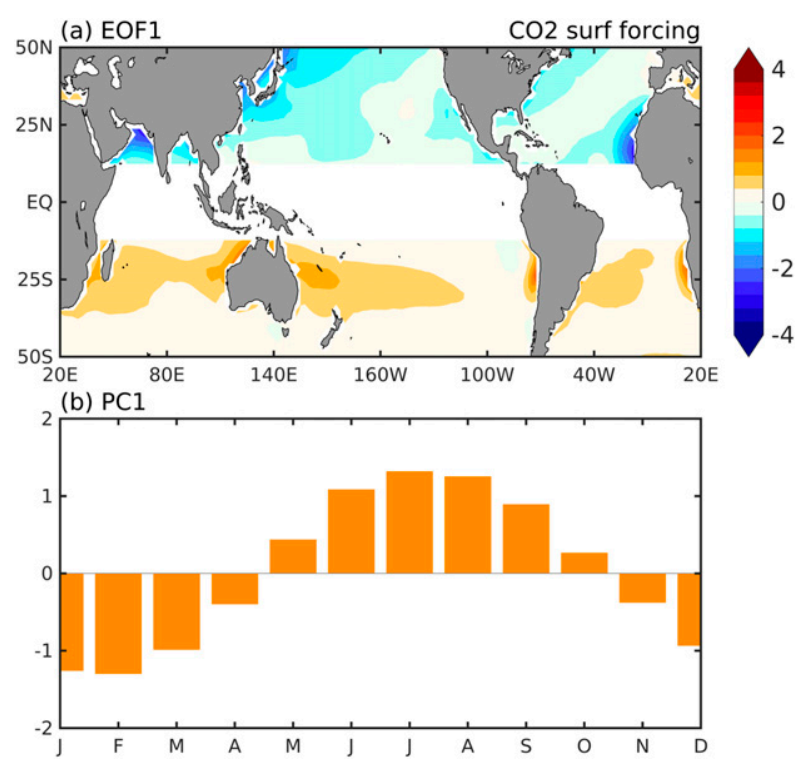

FIG. 8. (a) The first EOF of the radiative forcing due to quadrupling $\mathrm{CO}_{2}\left(\mathrm{~W} \mathrm{~m}^{-2}\right.$; positive downward) and (b) the corresponding normalized $\mathrm{PC}$ time series.

are examined here: one through the radiative forcing itself, and the other through pure ocean dynamical adjustment [mainly through adjustment in MLD proposed in Chen and Wang (2015) and Alexander et al. (2018)] to the radiative forcing.

The $\mathrm{CO}_{2}$ radiative forcing referred to here is the instantaneous radiative perturbation caused by change of $\mathrm{CO}_{2}$ concentration in the atmosphere. Despite the homogeneity in $\mathrm{CO}_{2}$ concentration distribution, the excited instantaneous radiative forcing can be geographically and temporally inhomogeneous (Huang et al. 2016). In particular, if the $\mathrm{CO}_{2}$ radiative forcing itself were stronger in summer than winter, it would serve as a factor for the enhancement of SST seasonal cycle. Following Huang et al. (2017), the instantaneous forcing is calculated from instantaneous atmospheric profiles from the CTRL simulation, using a Rapid
Radiative Transfer Model (Mlawer et al. 1997). Top-ofatmosphere (TOA) and surface radiation fluxes under the unperturbed and perturbed concentrations are calculated every $6 \mathrm{~h}$ for 5 years. Then the radiative forcing of quadrupling $\mathrm{CO}_{2}$ is obtained as the difference between the two sets of radiative fluxes. Since the focus of this research is SST, we present radiative forcing at sea surface in Fig. 8. The forcing is defined downward positive and thus positive values means warming effect. The leading PC of the surface radiative forcing also displays a pronounced annual cycle, peaking around July and reaching a minimum around February (Fig. 8 b). The negative (positive) loadings in the $\mathrm{NH}(\mathrm{SH})$ in the EOF1 pattern (Fig. 8a) act to reduce the climatological SST seasonal cycle. Note that the TOA radiative forcing has a tendency to reduce the SST seasonal cycle as well (now shown). This seasonality in the $\mathrm{CO}_{2}$-induced radiative flux is anticipated from the much thicker and hence more saturated optical depth of the summer atmosphere relative to the winter one, with the former being much less sensitive than the latter to the increase of $\mathrm{CO}_{2}$ concentration.

In addition to the instantaneous TOA forcing imposed by $\mathrm{CO}_{2}$ forcing, we also examine the total surface flux at the air-sea interaction. Figure 9 presents the changes in the seasonal cycle of the total downward surface flux due solely to the direct $\mathrm{CO}_{2}$ effect. Interestingly, the leading PC of changes in surface is in quadrature to the corresponding climatological PC (comparing the bars to the blue line in Fig. 9b), signaling a change in phase rather than amplitude. The leading EOF pattern of the total flux changes bears a considerable resemblance to the surface flux phase change diagnosed based on the A1B scenario simulations by the CMIP3 climate models and considered to be responsible for the phase delay of the subtropical SST seasonal cycle in Dwyer et al. (2012). As a result, neither the instantaneous radiative forcing of $\mathrm{CO}_{2}$ nor the total surface flux appears to be responsible for the enhanced (a) SHF EOF1

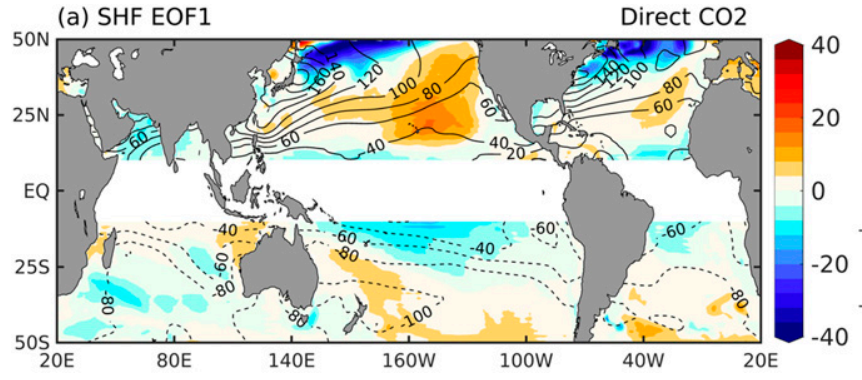

(b) PC1

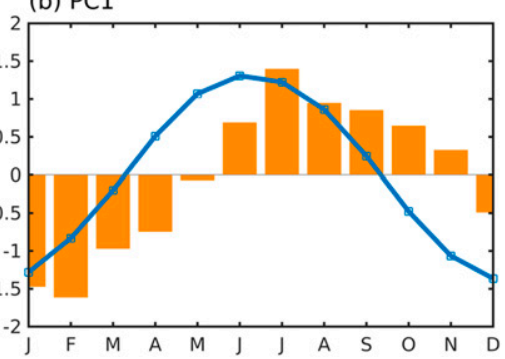

FIG. 9. (a) The first EOF of the total surface flux change due to direct $\mathrm{CO}_{2}$ effect ( $\mathrm{W} \mathrm{m}^{-2}$; positive downward), superimposed is the first EOF of the monthly climatology of the total surface flux in CTRL $\left(\mathrm{CI}=20 \mathrm{~W} \mathrm{~m}^{-2}\right)$. (b) The corresponding normalized PC time series. 
(a) EOF1 OHEAT - OCTRL

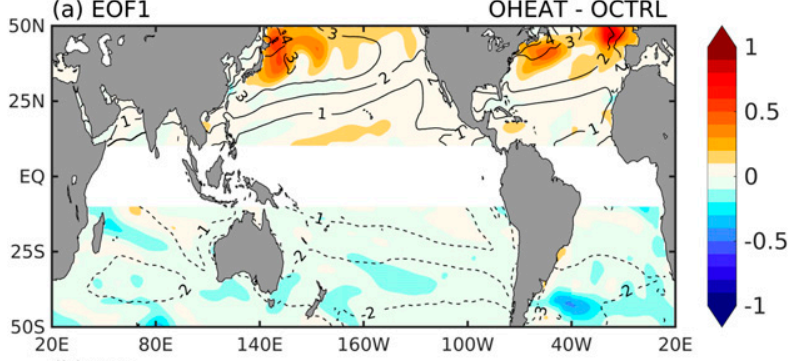

(b) PC1

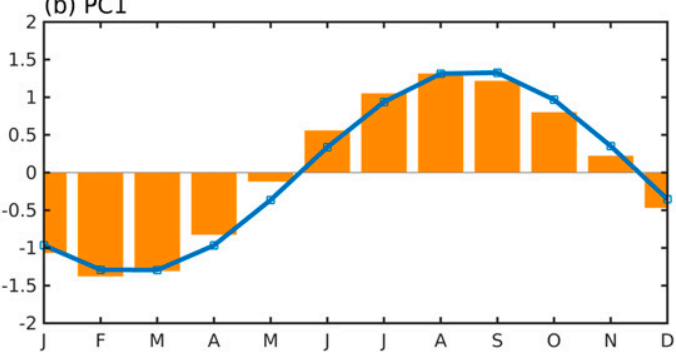

FIG. 10. (a) The first EOF of the SST changes in OHEAT OCTRL (color; K), overlaid by the first EOF of the monthly climatology in CTRL $(\mathrm{CI}=1 \mathrm{~K})$. (b) The corresponding normalized PC time series (bars for changes and line for climatology).

midlatitude SST seasonal cycle; this directs our attention to the ocean for its ultimate origin.

We further conduct a set of ocean-alone experiments with a spatially and temporally homogeneous heat flux $\left(1.5 \mathrm{~W} \mathrm{~m}^{-2}\right)$ added into the ocean surface, and all the dynamical and thermodynamical feedbacks from atmosphere are disabled by the prescription of the atmospheric forcings (see section $2 \mathrm{~b}$ ). As such, this constitutes a clean set of experiments wherein there is no seasonal cycle change from the sea surface fluxes so that we can cleanly identify the sole effect of the oceanic adjustments on the SST change in this ocean-alone context. It is surprising to see that, without the interaction with the atmosphere, the imposed homogeneous heating can still induce an enhancement in SST seasonal cycle in midlatitudes (Fig. 10), and the pattern bears a marked resemblance to that due to the direct $\mathrm{CO}_{2}$ effect (Fig. 4b) or the total response (Fig. 4a), with the enhancement confined in subpolar gyres in the $\mathrm{NH}$, but spread zonally in the $\mathrm{SH}$. This result strongly suggests that the SST seasonal cycle enhancement originates mainly from the oceanic adjustment to surface radiative forcing, and is independent of the spatial and temporal distribution of the radiative forcing. The fact of less smoothness in this enhancement pattern implies some role from the wind-related feedbacks in ironing out the small features in the pattern of the SST seasonal cycle response.

The significant contribution from the ocean dynamical adjustment is related to the MLD behaviors (Fig. 11).
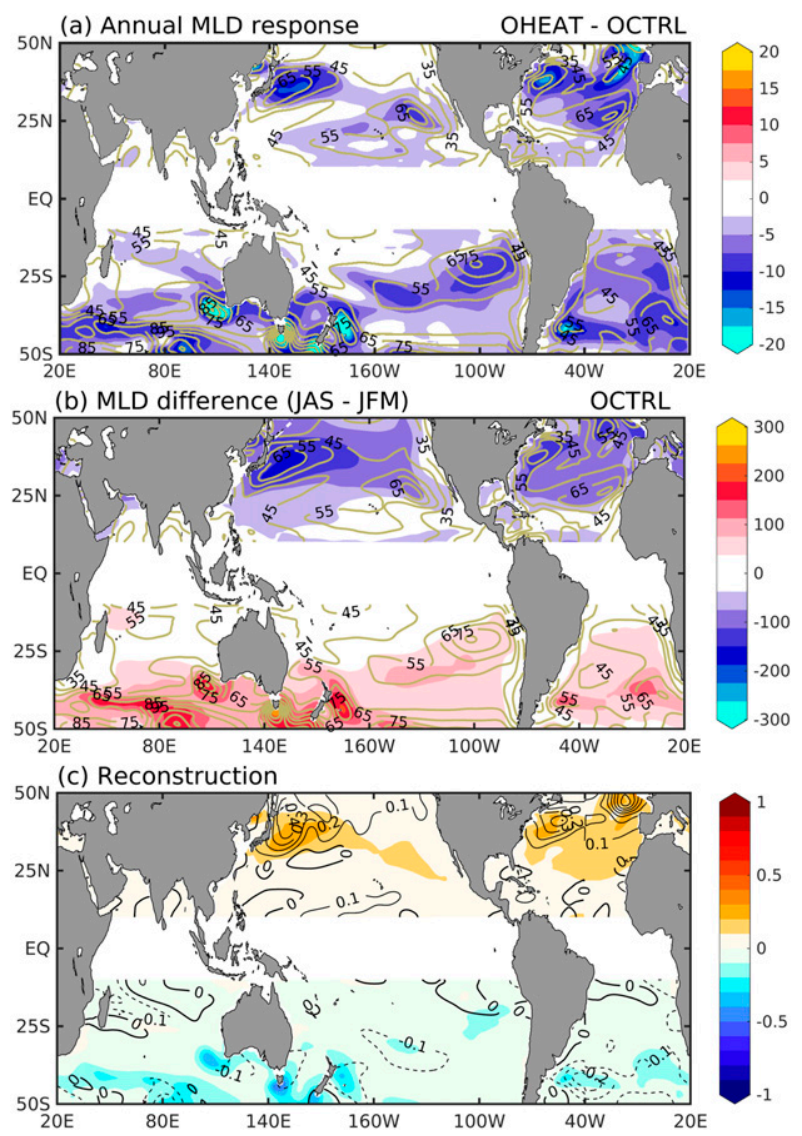

FIG. 11. (a) Mixed layer depth (MLD) annual mean change (color; $\mathrm{m}$ ) in OHEAT - OCTRL. (b) MLD difference between boreal summer (July-September) and boreal winter (JanuaryMarch) in OCTRL (color; m). (c) Prediction of SST seasonal cycle change (color; K) in OHEAT - OCTRL. The contours overlaid in (a) and (b) are the climatological annual mean MLD in OCTRL $(\mathrm{CI}=10 \mathrm{~m})$; overlaid in $(\mathrm{c})$ is the first EOF of the SST changes in OHEAT - OCTRL (same as color in Fig. 9a, CI =0.1 K). MLD is defined as the depth at which the potential density is $0.03 \mathrm{~kg} \mathrm{~m}^{-3}$ lower than density at $10 \mathrm{~m}$.

Specifically, a surface heating will lead to a more stratified upper layer due to greater ocean warming near the surface, inducing a shoaling of MLD over most of the global oceans. The shoaling MLD under global warming reduces the effective heat capacity of the surface ocean, and thus the SST responds to the seasonal forcing with a larger amplitude. The shoaling of the mean MLD mainly occurs in the midlatitude oceans, coinciding with the regions with the strongest SST seasonal cycle enhancements (cf. Figs. 11a and 10a). In addition, the ocean MLD is deeper in winter than summer (Fig. 11b), implying that a same amount of energy perturbation in summer is able to cause much larger warming than that in winter. Using the overall shallowing of the MLD $\left(\Delta H_{\text {Ann }}\right.$; Fig. 11a) and the mean background MLD 
difference between winter and summer $\left(\bar{H}_{\text {Diff }} ;\right.$ Fig. $\left.11 b\right)$ as two predictors, we may construct a multiple linear regression model for the SST seasonal cycle pattern change in OHEAT - OCTRL $\left(\Delta S_{\mathrm{OCN}}\right.$; Fig. $\left.10 \mathrm{~b}\right)$ as follows:

$$
\Delta S_{\mathrm{OCN}}=r_{\mathrm{Ann}} \Delta H_{\mathrm{Ann}}+r_{\mathrm{Diff}} \bar{H}_{\mathrm{Diff}}+C+E,
$$

where $r_{\text {Ann }}$ and $r_{\text {Diff }}$ are regression coefficients, $C$ is the constant offset, and $E$ is the error that cannot be fit into the regression. The spatial pattern correlation between the predicted change of SST seasonal cycle (i.e., $r_{\text {Ann }} \mathrm{MLD}_{\text {Ann }}+r_{\text {Diff }} \mathrm{MLD}_{\text {Diff }}+C$; Fig. $\left.11 \mathrm{c}\right)$ and the simulated one in OHEAT - OCTRL can reach 0.7, suggesting the potent role of MLD in the enhancement of SST seasonal cycle. In both North Pacific and North Atlantic basins, the predicted centers of the enhancement are somewhat displaced equatorward relative to the model simulated ones, leaving room for another mechanism unrelated to MLD: summer sea ice melting. The absence of ice in summer under warming allows for further warming during summer, but the presence of ice in winter restricts the SST to the freezing point of seawater $\left(\sim-1.8^{\circ} \mathrm{C}\right)$, curtailing the SST warming during winter (Alexander et al. 2018).

\section{Conclusions and discussion}

Midlatitude ocean and marine ecosystem have a welldefined annual cycle and the SST annual cycle there has been found to intensify under global warming. But the underlying mechanism for this intriguing phenomenon remains unclear. In this study we investigate the roles of wind stress, wind speed, and direct $\mathrm{CO}_{2}$ effects in determining the SST seasonal cycle response in midlatitudes to $\mathrm{CO}_{2}$ forcing, through the approach of feedback process disabling applied in a hierarchy of models. The modeling hierarchy here affords a systematic examination of the individual processes that contribute to, or even ultimately cause, the climate change phenomenon in question.

It is found that both of the direct $\mathrm{CO}_{2}$ effect and the total wind effect through wind stress-driven ocean dynamical feedback and wind speed feedback contribute to the overall enhancement of the SST seasonal cycle, with the former (latter) effect playing a more important role in the $\mathrm{NH}(\mathrm{SH})$. Unlike previous studies that ascribed the enhanced SST seasonal cycle (in the tropics) to thermodynamic wind speed feedback through the change of wind speed, our experiment results here reveal that the contribution from wind stress-driven oceanic adjustment is much more important, especially to the seasonal cycle enhancement in the SH midlatitudes.
But our conclusion should not be deemed contradictory to the earlier studies, as the argument proposed therein were intended for the tropical SST seasonal cycle response. Moreover, the seasonal cycle change of surface wind caused by direct $\mathrm{CO}_{2}$ effect shows marked similarity to those in total response, indicating that the wind changes in atmosphere are actually instigated by the direct $\mathrm{CO}_{2}$ effect. As a result, the origin of the enhanced SST seasonal cycle in midlatitudes should reside in direct $\mathrm{CO}_{2}$ effect, while the wind stress effect only plays a modulating role upon the original signal.

The direct $\mathrm{CO}_{2}$ effect could in principle affect the SST seasonal cycle through two pathways: one through the instantaneous radiative forcing itself, and the other through the ocean adjustment to the radiative forcing. Both diagnostics and ocean alone modeling demonstrate that it is the ocean adjustment that induces the SST seasonal cycle. Further analysis points to two MLD factors as the possible culprit: one is the overall shallowing of the MLD under surface thermal forcing, and the other is the mean background MLD difference between winter and summer. Since these two factors are similar in spatial distribution, diagnostics alone cannot distinguish their relative importance; further purposefully designed model experiments are warranted to tease out their quantitative contributions. Last, similar partial coupling approach to what has been done here should be encouraged with different climate models to test the robustness of the conclusions here.

Acknowledgments. This work is supported by the National Key Research and Development Program of China (2018YFA0605702) and the National Natural Science Foundation of China (NSFC; 91858210,41676002 and 41976006). It is also supported by the U.S. Department of Energy Office of Science Biological and Environmental Research (BER) as part of the Regional and Global Climate Modeling Program. The Pacific Northwest National Laboratory is operated for the Department of Energy by Battelle Memorial Institute under Contract DE-AC05-76RL01830. We acknowledge the World Climate Research Program's Working Group on Coupled Modeling, which is responsible for CMIP, and thank the climate modeling groups for producing and making available their model output at http://www.ipcc-data.org/sim/ gcm_monthly/AR5/Reference-Archive.html. For CMIP, the U.S. DOE's Program for Climate Model Diagnosis and Intercomparison provides coordinating support and led development of software infrastructure in partnership with the Global Organization for Earth System Science Portals. The authors also acknowledge the three anonymous reviewers for their valuable comments in improving the manuscript. 
Data availability statement. All the model data output has been archived on NERSC High Performance Storage System (HPSS) and can be accessed upon request to the corresponding authors.

\section{REFERENCES}

Alexander, M. A., J. D. Scott, K. D. Friedland, K. E. Mills, J. A. Nye, A. J. Pershing, and A. C. Thomas, 2018: Projected sea surface temperatures over the 21st century: Changes in the mean, variability and extremes for large marine ecosystem regions of northern oceans. Elementa: Sci. Anthropocene, 6, 9, https://doi.org/10.1525/ELEMENTA.191.

Biasutti, M., and A. H. Sobel, 2009: Delayed Sahel rainfall and global seasonal cycle in a warmer climate. Geophys. Res. Lett., 36, L23707, https://doi.org/10.1029/2009GL041303.

Carton, J. A., Y. Ding, and K. R. Arrigo, 2015: The seasonal cycle of the Arctic Ocean under climate change. Geophys. Res. Lett., 42, 7681-7686, https://doi.org/10.1002/2015GL064514.

Chen, C., and G. Wang, 2015: Role of North Pacific mixed layer in the response of SST annual cycle to global warming. J. Climate, 28, 9451-9458, https://doi.org/10.1175/JCLI-D-14-00349.1.

de Boyer Montégut, C., G. Madec, A. S. Fischer, A. Lazar, and D. Iudicone, 2004: Mixed layer depth over the global ocean: An examination of profile data and a profile-based climatology. J. Geophys. Res., 109, C12003, https://doi.org/10.1029/ 2004JC002378.

Dwyer, J. G., M. Biasutti, and A. H. Sobel, 2012: Projected changes in the seasonal cycle of surface temperature. J. Climate, 25, 6359-6374, https://doi.org/10.1175/JCLI-D-11-00741.1.

Follows, M. J., R. G. Williams, and J. C. Marshall, 1996: The solubility pump of carbon in the subtropical gyre of the North Atlantic. J. Mar. Res., 54, 605-630, https://doi.org/10.1357/ 0022240963213682.

Huang, Y., X. Tan, and Y. Xia, 2016: Inhomogeneous radiative forcing of homogeneous greenhouse gases. J. Geophys. Res. Atmos., 121, 2780-2789, https://doi.org/10.1002/2015JD024569.

_ , Y. Xia, and X. Tan, 2017: On the pattern of $\mathrm{CO}_{2}$ radiative forcing and poleward energy transport. J. Geophys. Res. Atmos., 122, 10 578-10 593, https://doi.org/10.1002/2017JD027221.

Keeling, R. F., A. Körtzinger, and N. Gruber, 2010: Ocean deoxygenation in a warming world. Annu. Rev. Mar. Sci., 2, 199229, https://doi.org/10.1146/annurev.marine.010908.163855.

Kushnir, Y., W. A. Robinson, I. Bladé, N. M. J. Hall, S. Peng, and R. Sutton, 2002: Atmospheric GCM response to extratropical SST anomalies: Synthesis and evaluation. J. Climate, 15, 2233-2256, https://doi.org/10.1175/1520-0442(2002)015<2233:AGRTES>2.0. $\mathrm{CO} ; 2$.

Liu, F., Y. Luo, J. Lu, and X. Wan, 2017: Response of the tropical Pacific Ocean to El Niño versus global warming. Climate Dyn., 48, 935-956, https://doi.org/10.1007/s00382-016-3119-2.

Liu, W., J. Lu, S. P. Xie, and A. Fedorov, 2018: Southern Ocean heat uptake, redistribution, and storage in a warming climate: The role of meridional overturning circulation. J. Climate, $\mathbf{3 1}$ 4727-4743, https://doi.org/10.1175/JCLI-D-17-0761.1.

Longhurst, A., 1995: Seasonal cycles of pelagic production and consumption. Prog. Oceanogr., 36, 77-167, https://doi.org/ 10.1016/0079-6611(95)00015-1.
Lu, J., and B. Zhao, 2012: The role of oceanic feedback in the climate response to doubling $\mathrm{CO}_{2}$. J. Climate, 25, 7544-7563, https://doi.org/10.1175/JCLI-D-11-00712.1.

Luo, Y., J. Lu, F. Liu, and W. Liu, 2015: Understanding the El Niño-like oceanic response in the tropical Pacific to global warming. Climate Dyn., 45, 1945-1964, https://doi.org/10.1007/ s00382-014-2448-2.

and O. Garuba, 2017: The role of ocean dynamical thermostat in delaying the El Niño-like response over the equatorial Pacific to climate warming. J. Climate, 30, 28112827, https://doi.org/10.1175/JCLI-D-16-0454.1.

—, F. Liu, and J. Lu, 2018: Response of the equatorial Pacific thermocline to climate warming. Ocean Dyn., 68, 1419-1429, https://doi.org/10.1007/s10236-018-1209-x.

Mann, M. E., and K. A. Emanuel, 2006: Atlantic hurricane trends linked to climate change. Eos, Trans. Amer. Geophys. Union, 87, 233-241, https://doi.org/10.1029/2006EO240001.

Menary, M. B., and R. A. Wood, 2018: An anatomy of the projected North Atlantic warming hole in CMIP5 models. Climate Dyn., 50, 3063-3080, https://doi.org/10.1007/s00382-017-3793-8.

Mlawer, E. J., S. J. Taubman, P. D. Brown, M. J. Iacono, and S. A. Clough, 1997: Radiative transfer for inhomogeneous atmospheres: RRTM, a validated correlated- $k$ model for the longwave. J. Geophys. Res., 102, 16663-16 682, https://doi.org/10.1029/97JD00237.

Neelin, J. D., B. Langenbrunner, J. E. Meyerson, A. Hall, and N. Berg, 2013: California winter precipitation change under global warming in the Coupled Model Intercomparison Project phase 5 ensemble. J. Climate, 26, 6238-6256, https://doi.org/ 10.1175/JCLI-D-12-00514.1.

Roe, G., 2009: Feedbacks, timescales, and seeing red. Annu. Rev. Earth Planet. Sci., 37, 93-115, https://doi.org/10.1146/ annurev.earth.061008.134734.

Simpson, I. R., T. A. Shaw, and R. Seager, 2014: A diagnosis of the seasonally and longitudinally varying midlatitude circulation response to global warming. J. Atmos. Sci., 71, 2489-2515, https://doi.org/10.1175/JAS-D-13-0325.1.

Sobel, A. H., and S. J. Camargo, 2011: Projected future seasonal changes in tropical summer climate. J. Climate, 24, 473-487, https://doi.org/10.1175/2010JCLI3748.1.

Stine, A. R., and P. Huybers, 2012: Changes in the seasonal cycle of temperature and atmospheric circulation. J. Climate, 25, 73627380, https://doi.org/10.1175/JCLI-D-11-00470.1.

Thomas, A. C., and Coauthors, 2018: Seasonal trends and phenology shifts in sea surface temperature on the North American northeastern continental shelf. Elementa: Sci. Anthropocene, 5, 48, https://doi.org/10.1525/ELEMENTA.240.

Thomson, R. E., and I. V. Fine, 2003: Estimating mixed layer depth from oceanic profile data. J. Atmos. Oceanic Technol., 20, 319-329, https:// doi.org/10.1175/1520-0426(2003)020<0319:EMLDFO>2.0.CO;2.

Timmermann, A., F. F. Jin, and M. Collins, 2004: Intensification of the annual cycle in the tropical Pacific due to greenhouse warming. Geophys. Res. Lett., 31, L12208, https://doi.org/10.1029/2004GL019442.

Trenberth, K. E., 1983: What are the seasons? Bull. Amer. Meteor. Soc., 64, 1276-1282, https://doi.org/10.1175/1520-0477(1983) 064<1276:WATS $>2.0$.CO;2.

Xie, S.-P., C. Deser, G. Vecchi, J. Ma, H. Teng, and A. T. Wittenberg, 2010: Global warming pattern formation: Sea surface temperature and rainfall. J. Climate, 23, 966-986, https://doi.org/10.1175/2009JCLI3329.1. 